Prof. Dr. Fausto Roberto Poço Viana - USP

Editor Responsável

ME. LAURA HADDAD - USP

ME. MARIA CELINA GIL REIS BOEIRA - USP

ME. PHELIPPE CELESTINO - USP

Editores

Comissão editorial

Camila Moreira Gomes - USP

Me. Danilo Silveira - USP

Me. Heloísa Helena Pacheco de Sousa - USP

Dr. Luiz Fernando Ramos - USP

Mateus Fávero - USP

Me. Saulo Vinícius Almeida - USP

Dra. Sayonara Pereira - USP

Me. Tainá Macedo Vasconcelos - USP

Maria Eduarda Andreazzi Borges - USP 
Revista Aspas

ppgac - USP

Editorial

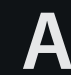

MORTE

DA

CULTURA

Editorial

Laura Haddad

Maria Celina Gil Reis Boeira

Phelippe Celestino 


\section{A MORTE DA CULTURA}

A nova cultura brasileira passa por um momento crítico: como em uma sequência das peças de um dominó que caem uma a uma, estamos presenciando uma sucessão de erros que resulta em um verdadeiro apagão cultural, perdendo-se muito do que já foi conquistado ao longo de anos e anos de luta pela comunidade artística, coletivos e entidades culturais.

Uma violência sem fim atrelada ao desmonte e a um cenário sombrio de muitas indefinições nos é apresentado de forma surreal pelo atual governo de Jair "Messias" Bolsonaro que, claramente, não se posiciona a favor da arte, da pluralidade, e que tem o dirigismo cultural como norte das atuais políticas públicas nessa área.

Se é intencional ou não, não sabemos - ou hesitamos saber devido ao absurdo que isso representa. O governo também não faz questão de deixar claro - ou deixa negando que deixou. O fato é que esse "delírio governista" esqueceu a diversidade cultural brasileira e a inter-relação desta com outras culturas de várias partes do mundo.

Ao extinguir o Ministério da Cultura em 2019 e atrelar a pasta ao Ministério do Turismo, encerrou-se também um período de importante desenvolvimento do fomento e da difusão cultural em nosso país, bem como a livre expressão artística promovida pelos governos de Luiz Inácio Lula da Silva e Dilma Rousseff.

Mário Frias, que assumiu a cultura em 2020, completa um ano de mandato com muitas polêmicas, críticas e travando qualquer possibilidade de continuidade da Lei de Incentivo à Cultura (antiga Lei Rouanet). Sérgio Camargo, presidente da Fundação Palmares é alvo de processo pela Coalizão Negra por Direitos. Diante dos nossos olhos museus e acervos queimam, literalmente, e a dita lei federal se tornou campo para a cruzada bolsonarista de perseguição contra aqueles que se mostrarem infiéis a sua doutrina ideológica extremista.

A Funarte agoniza e secretários de cultura de diversos Estados brasileiros cobram o atual governo diante de um cenário de incertezas e discursos desalinhados. 
A Lei Aldir Blanc favoreceu alguns poucos artistas, mascarando um processo complexo e triste de precarização e vulnerabilização social da classe artística frente à pandemia, obrigando os profissionais da arte a buscar outras oportunidades de trabalho para sobreviver em meio ao caos que se instaurou - ou fora promovido propositalmente (?) - nas áreas da saúde, educação, economia e cultura.

A pandemia da COVID19, decretada em março de 2020, ceifou até agora mais de 570 mil vidas. Dentre elas, muitos artistas, técnicos e colaboradores das artes da cena. $O$ setor cultural, em geral, foi um dos mais atingidos com a paralisação abrupta de projetos e o fechamento, em alguns casos irreversível, de teatros e demais espaços culturais.

Como seguir adiante? Como pensar a produção e a gestão de projetos culturais em um cenário como esse? Como entender criticamente isso que estamos vivendo? Há ainda que se falar em uma política pública estatal para a cultura? Onde a interlocução com a sociedade se faz presente?

Esta edição da Revista Aspas, que teve sua editoração iniciada antes da pandemia, ainda no longínquo 2019, vem cumprir essa demanda por reflexões e discussões sobre o papel do Estado nas políticas públicas para a cultura. Os trabalhos que aqui se apresentam, apesar de produzidos antes dessa nova era pandêmica, trazem em seu escopo análises sobre esse sistema ineficaz e nocivo que vem tentado se impor nos últimos anos no Brasil. Desde o golpe de 2016, a tônica tem sido a exploração dos artistas e demais profissionais das artes do palco, sob a alegação de um aparente empreendedorismo disfarçado de economia criativa, aliado a um projeto liberal de terceirização e exoneração das responsabilidades que o setor público possui em viabilizar, promover e oferecer bens culturais para a população do seu país.

A edição busca materializar um procedimento que vem sendo incorporado à Revista Aspas de deslocar o olhar para além das pesquisas realizadas no eixo Rio-São Paulo. A multiplicidade de discursos e realidades é ainda mais pungente quando o assunto são as políticas públicas, tendo em vista um país que ainda apresenta uma concentração cultural e uma desigualdade na distribuição de recursos para a cultura. O número conta com contribuições de pesquisadores de diferentes áreas e regiões do Brasil, cada um construindo um 
discurso sobre as políticas públicas nas artes da cena.

Abrindo a seção Especial teremos o artigo de Fernanda Areias Oliveira, Primeiras observações sobre os coletivos de teatro em São Luís, professora da Universidade Federal do Maranhão e coordenadora do Grupo de Pesquisa Laboratório de Tecnologia Dramática. Neste artigo, são discutidas as relações entre as políticas estatais de incentivo às artes cênicas no Estado do Maranhão em relação aos coletivos teatrais, especialmente da cidade de São Luís, de variados repertórios e linguagens. $O$ texto apresenta a necessidade de pensar as políticas públicas de maneira particular, entendendo as questões tocantes a cada região do país, ressaltando a relevância de uma formulação estatal de incentivo que não se paute apenas nos modelos sudestinos.

O artigo Movimento A Dança Se Move diante de retrocessos das políticas culturais estruturantes, de Helena Bastos, codiretora do Grupo Musicanoar, professora da Universidade de São Paulo e atual diretora do TUSP, e Vanessa Macedo, diretora da Cia. Fragmento de Dança, questiona como se dão as políticas públicas a partir do recorte específico da dança, principalmente pensando nas particularidades do trabalho continuado, na pesquisa e no desenvolvimento de uma linguagem autoral. A lógica neoliberal e a valorização da arte a partir de pressupostos mercadológicos contaminam os modos de produção artística, fazendo com que todas as etapas - criação, produção e difusão - das artes do corpo sejam alteradas. O Movimento Dança se Move e a costura de sua trajetória com os fomentos e incentivos públicos são a base de onde partem as análises sobre estratégias de resistência aos retrocessos nas políticas culturais das artes no Brasil ou ao terrível "capitalismo criativo".

Ainda nessa seção, Emerson de Paula Silva, professor da Universidade Federal do Amapá, e Luiz Gustavo Santos Cota, professor da Universidade do Estado de Minas Gerais, constroem um relato sobre as políticas de cultura na cidade de Ponte Nova. Em As Artes Cênicas e as Políticas Públicas de Cultura em Ponte Nova, Minas Gerais, os autores traçam um histórico das políticas culturais da cidade a partir do estabelecimento de um Sistema Municipal de Cultura, integrado ao Sistema Nacional. O artigo reforça ainda a importância de uma catalogação de grupos e artistas da cena como um caminho para a discussão das aplicações dos recursos públicos. Ao mesmo tempo, o 
texto aponta para a influência das políticas públicas de financiamento, principalmente pela via dos editais, na profissionalização de grupos que incorporaram, por exemplo, questões ligadas à prestação de contas e divulgação de suas obras à sua prática de trabalho.

Encerrando a seção Especial, Laura Haddad, atriz, diretora e produtora cultural, discute na Introdução ao tema "Políticas Públicas e Artes Cênicas: relações entre produção, mercado e Estado", a urgência de se discutir o assunto desta edição nesse momento histórico em particular. Enfrentamos hoje um momento de desmonte da cultura no país, agravado por um período de pandemia, que parece ter virtualizado muitos processos de criação e fruição dos bens culturais. A formação do gestor cultural também é um ponto levantado, apontado para a multiplicidade de saberes que essa área envolve, dado que não deixa de ser também um desafio diante dos mecanismos de incentivo que temos hoje. Laura reforça ainda a necessidade de encararmos as fragilidades do sistema atual como única maneira de construir políticas múltiplas, que pensem as realidades diversas e demandas específicas de cada situação.

Na seção de Artigos, apresentamos cinco textos que pensam os modos de produção teatral e suas relações com o Estado. Seja a partir do incentivo ou do sucateamento programático da cultura, o teatro e o poder público têm cruzado seus caminhos em uma relação ora de dependência, ora de questionamento ora de enfrentamento.

A seção se abre com o artigo Neoliberalismo e modos de produção teatral no Brasil: da pós-ditadura ao neofascismo, de Gustavo Guenzburger, artista, ativista, pesquisador e professor. O texto discute como o próprio meio teatral tem um papel na crise que se instaura nos seus modos de produção e políticas culturais, pensando como assumimos pressupostos e práticas neoliberais em nossos próprios processos. Desde o período da Ditadura civil militar no Brasil, parece ter havido um esmorecimento do papel do teatro como resistência ao autoritarismo. Se antes o teatro era um foco de luta social contra o regime, hoje não parece ter a mesma fonte de atuação; e o artigo atribui essa mudança principalmente ao processo de precarização que sofreu, além dos ataques aos seus meios materiais de realização. 
Também observando as contradições e fragilidades do Estado capitalista e sua relação com a cultura, Fernando Bustamante, atualmente doutorando da Universidade de São Paulo, discute no artigo Estado e financiamento teatral os movimentos teatrais ligados à classe trabalhadora, em oposição aos valores das classes dominantes que, a longo prazo, sobrepujam as possibilidades de apoio à cultura. Partindo do Théâtre Libre (Teatro Livre), de André Antoine, e seu desejo de estabelecimento de uma nova linguagem teatral que se ligou à classe trabalhadora, fortalecendo ainda a importância do financiamento independente, para além dos circuitos hegemônicos, o artigo chega até o Brasil dos dias de hoje, cujas estratégias de fomento são basicamente dependentes de políticas de um Estado capitalista neoliberal.

Pensando especificamente a questão da Lei de Fomento ao Teatro da cidade de São Paulo, Simone do Prado Romeo, atualmente doutoranda da Universidade de São Paulo, discute os principais aspectos da lei e como ela representa uma inovação no campo da cultura e políticas públicas no Brasil. $O$ artigo Particularidades da Lei de Fomento ao Teatro para a cidade de São Paulo inicia sua análise a partir da atuação do movimento Arte contra a Barbárie, surgido no fim dos anos 1990, de grande importância para a pauta dos debates sobre políticas culturais, na construção da Lei de Fomento e aprofunda a discussão sobre a importância de uma lei focada exclusivamente para o teatro - e também suas limitações.

No Rio Grande do Sul, o fechamento do Centro Cultural da Usina do Gasômetro motivou o artigo escrito por Ana Paula Parodi Eberhardt, atriz e produtora cultural pela Cambada de Teatro em Ação Direta Levanta Favela, Política Pública e Projeto Colonial: O Centro Cultural Usina do Gasômetro. O fechamento provocou uma mudança na trajetória de grupos de artes cênicas, que tiveram que mudar seus espaços de trabalho para outros locais distantes do circuito artístico da cidade. Mais do que apenas uma mudança de local, essa ação demonstrou o impacto danoso de desvalorização da cultura em um país que, cada vez mais, assume políticas neoliberais e privilegia o setor privado em detrimento do público.

Encerrando a seção de Artigos, Heloisa Marina da Silva, atriz, produtora e professora da Universidade Federal de Minas Gerais, traz o texto Teatro 
e a condição de pós-autonomia da arte, que questiona os limites da autonomia do teatro numa estrutura mercadológica do capitalismo tardio. A partir do conceito de pós-autonomia da arte, proposto por Nestor Garcia Canclini, o artigo questiona os termos "teatro comercial", "teatro não comercial" e "teatro de grupo", abordando as contradições dos diferentes processos, as expectativas do público e as relações com o Estado e poder financeiro, principalmente das políticas culturais. A reflexão está na pergunta: é possível um teatro isolado de estruturas mercadológicas?

A seção Desenho de Pesquisa conta com o artigo Resiliência e Sustentabilidade, de Giovanna Pereira de Souza, então aluna da Especialização em Produção Cultural em Artes Cênicas, cujo trabalho foi orientado pela professora Maria Alice Possani, da UNICAMP. A partir de entrevistas com grupos do interior de São Paulo, o trabalho investiga os desafios do fazer teatral que não são poucos. Partindo da experiência de teatro realizado de maneira coletiva e suas metodologias específicas, a autora investiga as lutas para estabelecer seus próprios espaços e para garantir sustentabilidade econômica diante dos múltiplos retrocessos na cultura e nas políticas públicas.

$\mathrm{O}$ artigo Formas e Funções das Políticas Públicas Brasileiras para a Cultura, de Natacha Dias, atualmente doutoranda da Universidade Estatual de Campinas, integra a seção Do lado de Fora do Teatro. A autora reflete sobre o modelo de publicização do Programa Fábricas de Cultura, dentro de um histórico de modelos de políticas públicas adotadas por gestores ao longo do tempo. Surgido como uma oportunidade de desenvolver potencialidades de jovens periféricos, além de escapar à violência cotidiana - frequentemente perpetrada pelo Estado - enfrenta hoje uma grande questão: as relações entre poderes público e privado, a partir dos modos de administração que transferem a gestão de serviços estatais para empresas privadas. Quais são as consequências dessa perda de limites?

Na seção Forma Livre, Ádia da Silva Freitas Anselmi, artista da dança, idealizadora da Sutil Companhia de Dança, traz uma visão sensível sobre a profissão do artista e suas escolhas de vida no documentário Viver de Dança. A partir de uma série de entrevistas com profissionais de nacionalidades diversas, a obra audiovisual, realizada em 2019 durante residência artística em 
Buenos Aires, realiza-se a partir da ideia de que a diversidade é a premissa da arte.

Por fim, encerramos a edição ainda na seção Forma Livre com o artigo Memórias do Programa Vocacional: movimentos ao redor de emancipação, igualdade e política, de Miguel Atticciati Prata, ator, pesquisador e gestor, mestre pela Universidade de São Paulo. $O$ artigo apresenta fragmentos da Revista Vocacional Memória: percorrendo vozes e ecos de um projeto público, além de relatos da própria experiência empírica do autor com o projeto, que se construiu como um espaço de possibilidades emancipatórias e de identificação de pungências artísticas.

São, portanto, apresentadas ao longo da edição reflexões que apresentam exemplos de produção e gestão cultural e ao mesmo tempo questionam as condições que as tornaram viáveis, ou ainda, que as colocaram em crise. Diferentemente da conduta administrativa federal, foram feitos por pessoas habilitadas e especialistas no assunto. São estudos de caso e realizações que trazem perguntas, provocam o debate e buscam apresentar propostas, ideias e perspectivas.

Assim, a Revista Aspas espera que essa edição possa contribuir e fomentar novas pesquisas nessa área tão cara e importante para a sobrevivência e manutenção das artes cênicas no Brasil. A leitura e a apreciação do conteúdo que compõe essa publicação apontam certamente para essa direção: da urgência e da necessidade de se consolidar os estudos em andamento e de se estabelecer novas pesquisas perante esse cenário sombrio que ora nos é apresentado. Diante das dificuldades e dos obstáculos mais uma vez as artes se reinventam, se transformam e resistem ao obscurantismo e à repressão.

Desejamos a todas e a todos uma leitura rica e proveitosa!

25 de agosto de 2021 Laura Haddad, Maria Celina Gil, Phelippe Celestino Editores da Revistas Aspas 9.2 